\title{
Glycosylating Effectors of Legionella pneumophila: Finding the Sweet Spots for Host Cell Subversion
}

\author{
Yury Belyi ${ }^{1, *(\mathbb{D})}$, Nadya Levanova ${ }^{2}$ and Gunnar N. Schroeder ${ }^{3, *(\mathbb{D}}$ \\ 1 Laboratory of Molecular Pathogenesis, Gamaleya Research Centre, 123098 Moscow, Russia \\ 2 Stockert GmbH, D-79111 Freiburg, Germany; nlevanova@stockert.de \\ 3 Wellcome-Wolfson Institute for Experimental Medicine, Queen's University Belfast, Belfast BT9 7BL, UK \\ * Correspondence: belyi@gamaleya.org (Y.B.); g.schroeder@qub.ac.uk (G.N.S.)
}

check for updates

Citation: Belyi, Y.; Levanova, N.; Schroeder, G.N. Glycosylating Effectors of Legionella pneumophila: Finding the Sweet Spots for Host Cell Subversion. Biomolecules 2022, 12, 255. https://doi.org/10.3390/ biom12020255

Academic Editor: Travis Beddoe

Received: 22 October 2021

Accepted: 31 January 2022

Published: 4 February 2022

Publisher's Note: MDPI stays neutral with regard to jurisdictional claims in published maps and institutional affiliations.

Copyright: (C) 2022 by the authors. Licensee MDPI, Basel, Switzerland. This article is an open access article distributed under the terms and conditions of the Creative Commons Attribution (CC BY) license (https:// creativecommons.org/licenses/by/ $4.0 /)$.

\begin{abstract}
Work over the past two decades clearly defined a significant role of glycosyltransferase effectors in the infection strategy of the Gram-negative, respiratory pathogen Legionella pneumophila. Identification of the glucosyltransferase effectors Lgt1-3, specifically modifying elongation factor eEF1A, disclosed a novel mechanism of host protein synthesis manipulation by pathogens and illuminated its impact on the physiological state of the target cell, in particular cell cycle progression and immune and stress responses. Recent characterization of SetA as a general O-glucosyltransferase with a wide range of targets including the proteins Rab1 and Snx1, mediators of membrane transport processes, and the discovery of new types of glycosyltransferases such as LtpM and SidI indicate that the vast effector arsenal might still hold more so-far unrecognized family members with new catalytic features and substrates. In this article, we review our current knowledge regarding these fascinating biomolecules and discuss their role in introducing new or overriding endogenous post-translational regulatory mechanisms enabling the subversion of eukaryotic cells by L. pneumophila.
\end{abstract}

Keywords: Legionella pneumophila; intracellular pathogen; host manipulation; virulence mechanism; type 4 secretion system; effector glycosyltransferase

\section{Introduction}

Legionella pneumophila is a Gram-negative opportunistic human pathogen, causing the serious pulmonary infection Legionnaires' disease or the flu-like catarrhal illness Pontiac fever [1,2]. Within aerosol droplets, the bacteria reach human lungs and proliferate in host cells-macrophages, monocytes, and bronchoalveolar epithelial cells [3].

The capability of Legionella to infect eukaryotic cells depends upon highly specific activities of effector proteins, biomolecules, which the bacteria deliver into target cells using the Dot/Icm type 4B secretion system (T4BSS) [4,5]. Coordinated action of the effectors results in inhibition of antibacterial activities and the reprogramming of diverse host cell processes to support replication in the Legionella-containing vacuole (LCV). Among the fundamental processes manipulated by Legionella are general metabolism, phagosome maturation, ubiquitination, apoptosis, small GTPase signaling, autophagy, transcription, protein synthesis, and cytoskeletal and mitochondrial dynamics (recently reviewed in [6-10]). Moreover, several so-called metaeffectors directly target and regulate the activity of other effectors (reviewed in [11]).

L. pneumophila has a biphasic life cycle, characterized by phenotypic transition from a replicative to a virulent, transmissive form, which shows increased expression of virulence factors including many T4BSS effectors. In broth culture, the phenotypic adaptation occurs during the transition from exponential to early stationary growth phase [12-14].

The number of Legionella effectors is exceptionally high, and in a single species, L. pneumophila, it increased from 30 in 2007 to 330 in 2020 [7,15-18]. The functions and the biochemical activities of most effectors remain unknown; however, the activities assigned so 
far are incredibly diverse. They include not only catalysis of well-known reactions exploited by many bacterial pathogens such as phospholipid cleavage [19], phosphorylation [20,21], and ADP-ribosylation [22,23], but also "unusual" or unique reactions such as glutamylation, reversible AMPylation or phosphocholination, and activities previously assumed to only be performed by eukaryotic enzymes, for example ubiquitination (reviewed in [7,24-26]). Various non-enzymatic protein-protein and protein-lipid interactions add extra layers of complexity to the biochemical landscape of Legionella effector biomolecules [9,27-29].

Post-translational modification of host proteins by sugar attachment, known as glycosylation, and accomplished by bacterial glycosyltransferases (GTs) (Figure 1A), has attracted much attention after the pioneering studies of K. Aktories and M. Popoff on secreted Clostridioides difficile cytotoxins (Table 1) [30]. In the following years, the list of bacterial glycosyltransferase virulence factors grew considerably due to the discovery of additional toxins of Clostridia, Photorhabdus, Yersinia, Chlamydia, and Escherichia coli [31,32]. Seminal work guided by K. Aktories and M. Popoff on L. pneumophila led to the identification of the first T4BSS glucosylating effector Lgt1 [33,34]. Soon thereafter, several other glycosylating effectors were identified and thoroughly studied in various bacterial pathogens, for example arginine-glycosylating effectors from Salmonella enterica Typhimurium (SseK), pathogenic E. coli, and Citrobacter rodentium (NleB) [35-39]. Several excellent reviews on glycosylation mechanisms of this group have appeared in recent years [40-42]. At the same time, new glycosylating effectors of L. pneumophila, SetA, LtpM, and SidI, have been identified. Here, we provide an overview of the considerable progress achieved in the last years in the biochemical and functional characterization of L. pneumophila's glycosyltransferase arsenal.

A

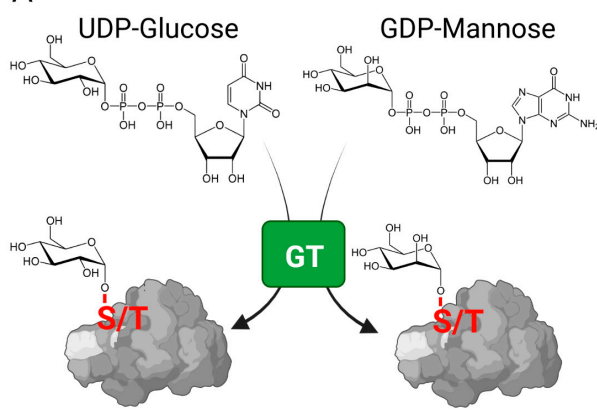

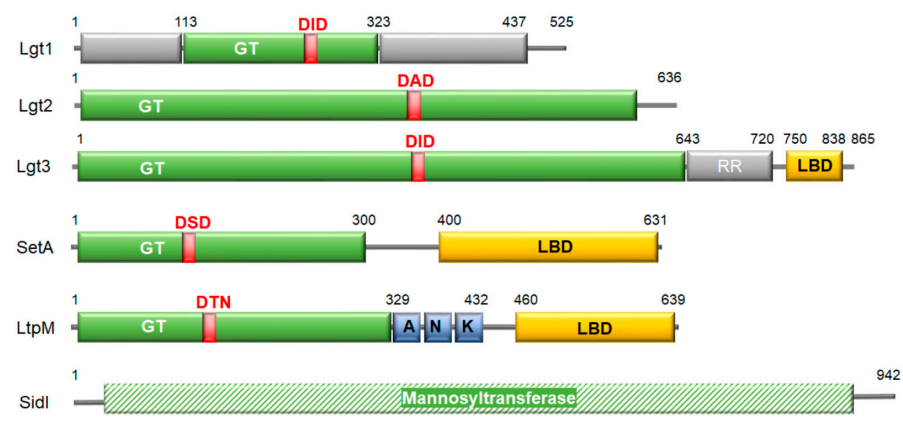

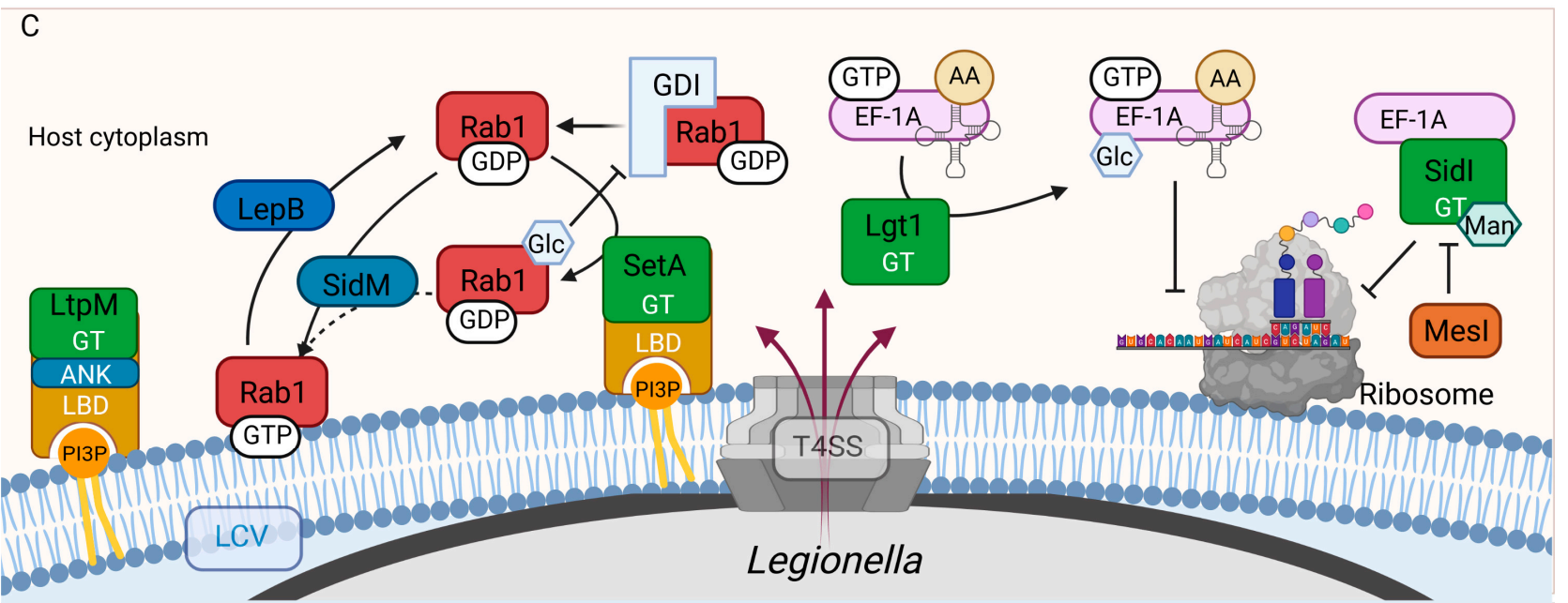

Figure 1. (A) Scheme depicting the glycosylation reaction carried out by glucosyl- and mannosyltransferases. (B) Comparison of the domain structure of glycosyltransferase effectors of L. pneumophila. Red letters show catalytically important motifs. Regions of unknown function are colored in grey. (C) Scheme 
illustrating the subcellular targeting and function of the L. pneumophila glycosyltransferase effectors during infection. AA, Amino acid; ANK, Ankyrin repeats; GDI, GDP dissociation inhibitor; GT, Glycosyltransferase; Glc, Glucose moiety; LBD, Lipid-binding domain; LCV, Legionella containing vacuole; Man, GDP-Mannose, RR, Repeat Region; T4SS, type IV secretion system.

Table 1. Glycosyltransferase toxins and effectors.

\begin{tabular}{|c|c|c|c|c|c|c|}
\hline $\begin{array}{c}\text { Protein } \\
\text { Superfamily }\end{array}$ & Protein Name & $\begin{array}{c}\text { Donor } \\
\text { Substrate }\end{array}$ & $\begin{array}{l}\text { CAZY } \\
\text { Classification, } \\
\text { Reaction Type }\end{array}$ & $\begin{array}{c}\text { Acceptor Protein } \\
\text { Target } \\
\text { (Amino Acid Residue) }\end{array}$ & $\begin{array}{l}\text { Peptide } \\
\text { Recognition } \\
\text { Sequence }\end{array}$ & $\begin{array}{l}\text { First } \\
\text { Discovery } \\
\text { Citation }\end{array}$ \\
\hline \multirow{8}{*}{ 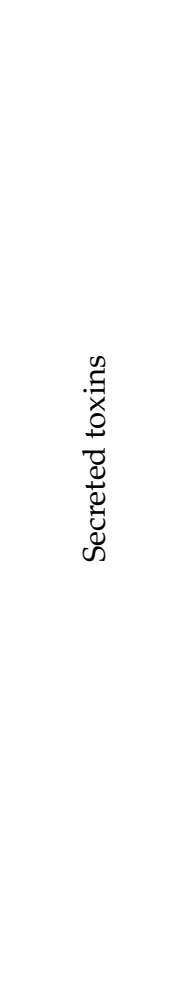 } & $\begin{array}{l}\text { TcdA of } \\
\text { C. difficile }\end{array}$ & UDP-Glc & $\begin{array}{l}\text { GT-A, GT44, } \\
\text { retaining, } \\
\text { O-linked }\end{array}$ & $\begin{array}{c}\text { Small GTPases } \\
\text { Rho/Ras/Rac/Rap } \\
\text { (Threonine) }\end{array}$ & Unknown & [43] \\
\hline & $\begin{array}{l}\text { TcdB of } \\
\text { C. difficile }\end{array}$ & UDP-Glc & $\begin{array}{l}\text { GT-A, GT44, } \\
\text { retaining } \\
\text { O-linked }\end{array}$ & $\begin{array}{c}\text { Small GTPases } \\
\text { Rho/Ras/Rac/Rap/Ral } \\
\text { (Threonine) }\end{array}$ & $\begin{array}{l}\text { YAPVFDAY } \\
\text { [44] }\end{array}$ & {$[30]$} \\
\hline & $\begin{array}{l}\text { TcsL of } \\
\text { C. sordellii }\end{array}$ & UDP-Glc & $\begin{array}{l}\text { GT-A, GT44, } \\
\text { retaining } \\
\text { O-linked }\end{array}$ & $\begin{array}{c}\text { Small GTPases } \\
\text { Rho/Ras/Rac/Rap/Ral } \\
\text { (Threonine) }\end{array}$ & Unknown & [45] \\
\hline & $\begin{array}{l}\text { TcsH of } \\
\text { C. sordellii }\end{array}$ & UDP-Glc & $\begin{array}{l}\text { GT-A, GT44, } \\
\text { retaining } \\
\text { O-linked }\end{array}$ & $\begin{array}{l}\text { Small GTPases } \\
\text { Rho/Ras/Rac } \\
\text { (Threonine) }\end{array}$ & Unknown & [46] \\
\hline & $\begin{array}{c}\text { TpeL of } \\
\text { C. pefringens }\end{array}$ & $\begin{array}{l}\text { UDP-GlcNAc/ } \\
\text { UDP-Glc }\end{array}$ & $\begin{array}{l}\text { GT-A, GT44, } \\
\text { retaining } \\
\text { O-linked }\end{array}$ & $\begin{array}{c}\text { Small GTPases } \\
\text { Ras/Rac/Rap/Ral } \\
\text { (Threonine) }\end{array}$ & Unknown & [47] \\
\hline & $\begin{array}{l}\text { TcnA of } \\
\text { C. novyi }\end{array}$ & UDP-GlcNAc & $\begin{array}{l}\text { GT-A, GT44, } \\
\text { retaining } \\
\text { O-linked }\end{array}$ & $\begin{array}{c}\text { Small GTPases } \\
\text { Rho/Rac (Threonine) }\end{array}$ & Unknown & [48] \\
\hline & $\begin{array}{l}\text { PaTox of } \\
\text { P. asymbiotica }\end{array}$ & UDP-GlcNAc & $\begin{array}{c}\text { GT-A, retaining } \\
\text { O-linked }\end{array}$ & $\begin{array}{l}\text { Rho/Ras family of } \\
\text { small GTPases } \\
\text { (Tyrosine) }\end{array}$ & Unknown & [49] \\
\hline & $\begin{array}{l}\text { YGT of } \\
\text { Y. mollaretii }\end{array}$ & UDP-GlcNAc & $\begin{array}{c}\text { GT-A } \\
\text { O-linked }\end{array}$ & $\begin{array}{l}\text { Rab5, Rab31 } \\
\text { (Threonine) }\end{array}$ & Unknown & {$[50]$} \\
\hline \multirow{6}{*}{ 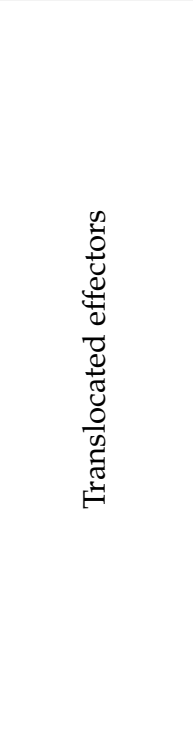 } & $\begin{array}{c}\text { Lgt1-3 of } \\
\text { L. pneumophila }\end{array}$ & UDP-Glc & $\begin{array}{l}\text { GT-A, GT88 } \\
\text { retaining } \\
\text { O-linked }\end{array}$ & eEF1A, Hbs1 (Serine) & $\begin{array}{c}\text { "X-K-X-S-F-K- } \\
Y / F-A-W-X " \\
{[51]}\end{array}$ & [33] \\
\hline & $\begin{array}{c}\text { SetA of } \\
\text { L. pneumophila }\end{array}$ & UDP-Glc & $\begin{array}{c}\text { GT-A, retaining } \\
\text { O-linked }\end{array}$ & $\begin{array}{l}\text { Multiple Rab1A, Snx1 } \\
\text { (Serine/Threonine) }\end{array}$ & $\begin{array}{l}\text { "S/T-X-L- } \\
\mathrm{P} / \mathrm{G} " \\
{[52]}\end{array}$ & [53] \\
\hline & $\begin{array}{c}\text { LtpM of } \\
\text { L. pneumophila }\end{array}$ & UDP-Glc & Not assigned & unknown & Unknown & {$[54]$} \\
\hline & $\begin{array}{c}\text { SidI of } \\
\text { L. pneumophila }\end{array}$ & GDP-mannose & Not assigned & unknown & Unknown & [53] \\
\hline & $\begin{array}{c}\text { NleB of } \\
\text { C. rodentium, } \\
\text { pathogenic } E \text {. } \\
\text { coli }\end{array}$ & UDP-GlcNAc & $\begin{array}{l}\text { GT-A, GT8, } \\
\text { retaining } \\
\text { N-linked }\end{array}$ & $\begin{array}{c}\text { Death domain proteins } \\
\text { (Arginine) }\end{array}$ & $\begin{array}{l}\text { "WR" motif } \\
{[55]}\end{array}$ & {$[36]$} \\
\hline & $\begin{array}{c}\text { SseK of } \\
\text { S. typhimurium }\end{array}$ & UDP-GlcNAc & $\begin{array}{l}\text { GT-A, GT8, } \\
\text { retaining } \\
\text { N-linked }\end{array}$ & $\begin{array}{l}\text { Death domain proteins } \\
\text { (Arginine) }\end{array}$ & $\begin{array}{c}\text { “WR" motif } \\
{[55]}\end{array}$ & [56] \\
\hline
\end{tabular}

\section{L. pneumophila Glucosyltransferases 1-3 (Lgt1-3)}

Lgt1 (Lpg1368, WP_010947098.1) was the first (and, to our knowledge, the only) Legionella T4BSS effector directly isolated from Legionella culture $[33,57]$. It was identified by 
$\mathrm{NH}_{2}$-terminal amino acid sequencing of the protein purified from L. pneumophila cells and consisted of 525 amino acid residues with a molecular mass of $60 \mathrm{kDa}$ and an isoelectric point of 7.0 [33]. The primary amino acid sequence shared little homology overall with characterized NCBI protein database entries; however, the central region showed some similarity to the enzymatic domain of large $C$. difficile glucosylating toxins. Several amino acid residues of the catalytic core including a DxD motif, the hallmark of many glycosyltransferases, were conserved, and it was established that, much like $C$. difficile toxins A and B, Lgt1 used UDP-glucose, but no other sugars, as a donor in the glucosylation reaction $[34,58]$.

Following on from this discovery, a bioinformatic search for similar sequences in the six genomes of L. pneumophila strains (Philadelphia-1, Corby, Lens, Paris, 2300/99 Alcoy, and 130b) available at that time disclosed a panel of open reading frames encoding proteins containing a region of significant homology to Lgt1 [59]. Apart from this region, the proteins demonstrated considerable amino acid sequence variations and did not display antigenic cross-reactivity with the specific polyclonal sera. Consequently, they were grouped into three subfamilies: Lgt1 (Lpg1368, WP_010947098.1), Lgt2 (LegC8, Lpg2862, WP_010948548.1), and Lgt3 (LegC5, Lpg1488, WP_010947217.1) (Figure 1B). Interestingly, clinical isolates of L. pneumophila contain more often the full set of Lgt enzymes, while the environmental isolates in many instances only encoded Lgt1 and Lgt3 [60]. Using the CyaA calmodulin-dependent adenylate cyclase or TEM- $1 \beta$-lactamase reporter systems, the efficient translocation of Lgt1-3 into host cells by T4BSS was demonstrated [61-63].

Recombinant Lgt2 and Lgt3 demonstrated glucosylation activities identical to that of Lgt1 [64]. All three effectors glucosylated eukaryotic elongation factor 1A (eEF1A) [34], an abundant, evolutionary conserved $\mathrm{G}$ protein in eukaryotes that plays a pivotal role in protein synthesis (Figure 1C); eEF1A delivers amino acylated tRNAs to the A-site of mRNA-charged ribosomes in a GTP-dependent manner [65]. The addition of purified Lgt1, Lgt2, or Lgt3 to in vitro translation assays or delivery of the proteins into mammalian cells by electroporation resulted in a dose-dependent inhibition of protein synthesis and the death of the targeted cells $[34,64,66]$.

Lgt1-3 glucosylate eEF1A exclusively on the residue serine-53, which is located on a protruding flexible loop in the G domain near the switch-I region of the protein [51]. The most efficient glucosylation of eEF1A occurs if it is GTP-loaded and forms part of the elongation-competent ternary complex consisting of eEF1A, GTP, and aminoacyl-tRNA [67]. The switch-I region of eEF1A is essential for the binding of GTP and undergoes major conformational changes upon GTP- and GDP-exchange, resulting in repositioning of the flexible loop [68]. This indicates that the conformation of eEF1a and especially of the loop containing the target amino acid residue determines accessibility for Lgt1-3 and modification efficiency. The modification of serine- 53 in eEF1A in turn might alter the conformational dynamics and/or accessibility of this important region, rendering the complex dysfunctional [69].

Interestingly, serine-53 of eEF1A can be subject to phosphorylation in mammalian cells [70]. Analysis of the consequences of this modification in yeast showed that a strain encoding the phosphomimetic glutamate instead of serine- 53 was not viable, whereas the corresponding alanine mutant variant survived, displaying growth and protein synthesis defects $[66,71]$. This underlines the critical nature of this residue and suggests that reversible serine-53 phosphorylation might dynamically control the pool of eEF1A available for protein synthesis in uninfected cells. Moreover, an increasing number of post-translational modifications on eEF1A, directing its involvement in various processes beyond translation, is reported [72-75]. Intriguingly, phosphorylation of serine-53 was proposed to enhance the interaction of eEF1A with phosphatidylinositol (PI) 4-kinase (PI4K) III $\beta$, leading to activation of the PI4K [73]. L. pneumophila dedicates a set of effectors to the manipulation of PI phosphate (PIP) membrane lipids. Legionella effector MavQ specifically catalyzes the production of PI3P, which is phosphorylated by LepB to yield PI(3,4)P2 and finally is dephosphorylated by SidF to make PI4P, and it is suggested that it also highjacks PI4K 
III $\beta$ to enrich the membrane of the LCV in PI4P [76,77]. In which way the glucosylation of eEF1A might affect this and if this modification could override or mimic phosphorylation or other host cell modifications is to be determined.

The minimal fragment of eEF1A, subjected to efficient in vitro glucosylation by Lgt1-3 was the decapeptide 50-GKGSFKYAWV-59 [51]. BLAST search with this minimal peptide sequence as a query retrieved Hsp70 subfamily B suppressor 1 (Hbs1) [78], as another putative eukaryotic substrate. Efficient modification of yeast and human recombinant Hbs1 by Lgt1 was subsequently demonstrated in vitro [51]. Hbs1 is an important component of the eukaryotic RNA quality control system. Specifically, ribosomes, stalled in elongation due to inhibitory secondary structures, nonsense mutations, etc., are rescued by Hbs1 in complex with the release factor (RF) 1-related protein Dom34 [79]. Whether the glucosylation of Hbs1 by Lgt1 affects its functions and leads to increased proportions of stalled ribosomes remains unclear.

During infection, Lgt1-3 have been implicated in the manipulation of several host cell processes, first and foremost, the inhibition of protein synthesis. The translation arrest does not cause immediate cytotoxicity, but could contribute to the killing of the host at the final stage of the Legionella-phagocyte interaction [80]. The inhibition of translation elongation by Lgt1-3 influences several host processes, for example the cell cycle, preventing entry into the S-phase, which otherwise would be detrimental for intracellular replication [81,82] and the IRE1-induced unfolded protein response (UPR) [83,84]. Moreover, in macrophages, the inhibition of protein synthesis caused by Lgt1-3 and the effectors SidI and SidL shapes a specific immune response $[85,86]$. On the one hand, it activates mitogen-activated protein kinase (MAPK) signaling and leads to the reduced production of $I_{K} B$, the inhibitor of the NF$\mathrm{KB}$ transcription factor, leading to sustained activation of NF-kB-induced transcription of, for example, cytokine genes such as $i l 23 \alpha[85,86]$. However, on the other hand, inhibition of protein synthesis prevents that transcriptional changes are translated into identical changes of the proteome. However, some selected transcripts, for example $i l-1 \alpha$, escape this blockade [87]. As protozoa do not encode mammalian immune mediators, the role of Lgt1-3 and other protein synthesis inhibitors is likely the control of fundamental stress responses and provision of free amino acids and other nutrients, facilitating host exploitation. Bearing in mind numerous interacting partners of eEF1A and "moonlighting" functions of the protein, additional unidentified processes are also likely affected.

The use of the three Lgt effectors with identical biochemical activity by L. pneumophila is perplexing, even more so considering that L. pneumophila uses at least four additional effectors (SidI (see below), LegK4, SidL, and RavX) to interfere with translation [88]. The functional redundancy of Legionella effectors in human macrophages is common, and the accumulation of many highly-related effectors is mainly associated with the evolutionary pressure to be prepared to successfully manipulate diverse protozoan hosts in the environment [89]. In line with this, a L. pneumophila strain lacking $\lg t 1, \lg t 2, \lg t 3$, sidI, and sidL showed decreased replication in the amoeba Dictyostelium discoideum, but no replication defect in macrophages [85,86].

However, while replication assays indicate some level of redundancy, there is also evidence pointing to distinct roles of Lgt1-3 during infection: (1) in L. pneumophila, the levels of Lgt1 and Lgt2 strongly increased in the stationary phase of bacterial growth, both in liquid culture and in amoebae, while Lgt3 was detectable in the lag- (pre-exponential) phase of cultivation under both conditions [64,68]; (2) Lgt1-3 contain different accessory domains (Figure 1B); for instance, Lgt3 contains a $\mathrm{COOH}$-terminal region of amino acid repeats and a lipid-binding domain (LBD), which binds phosphatidylinositol-3-phosphate (PI3P) in vitro [90], suggesting different subcellular targeting of Lgt3 in the host; (3) in ectopicexpression experiments, Lgt1-3 showed a different efficiency in blocking thapsigargininduced XBP1 mRNA splicing, a key step for the IRE1-mediated UPR [83,84]. How their different expression profiles and accessory domains and the interplay with other effectors might translate into different functions, for example, the targeting of different proteoforms of eEF1A, remains to be dissected. 


\section{Subversion of Eukaryotic Vesicle Trafficking A (SetA)}

A genetic screen in Saccharomyces cerevisiae identified several ectopically expressed effectors that induced significant cytotoxicity, had tropism to secretory organelles, and delayed the trafficking of secretory proteins to the yeast vacuole [53]. The latter phenomenon, subversion of eukaryotic vesicle trafficking, gave the name to SetA (Lpg1978, WP_010947694.1). The protein was expressed in the post-exponential growth phase and translocated by the T4BSS [53]. Like Lgt1-3, SetA contains a conserved functional glycosyltransferase DxD motif and a typical sugar-binding triad, which is located at the $\mathrm{NH}_{2}$-terminus of the $73 \mathrm{kDa}$ protein (Figure 1A) [53,91]. Recombinant SetA possessed glycohydrolase and autoglucosylation activities using UDP-glucose as a donor substrate, and the DxD motif was essential for catalytic activity and cytotoxicity in yeast and mammalian cells $[53,91]$.

The hunt for substrates of SetA revealed that, in contrast to Lgt1-3, SetA is a very promiscuous glycosyltransferase. Autoradiography-based assays combined with mass spectrometry showed that recombinant SetA modified the histones $\mathrm{H} 4$ and $\mathrm{H} 3.1$ as artificial substrates [91] and actin, vimentin, and the chaperonin protein CCT5 in crude eukaryotic cell lysate [92]. A screen for effectors, which can modulate the function of the transcription factor EB (TFEB), disclosed that ectopically-expressed SetA glucosylated TFEB and thus interfered with its interaction with 14-3-3 proteins, enhancing the nuclear localization of the factor [93]. Since TFEB is a regulator of homeostasis of amino acids in eukaryotic cells, manipulation by SetA could also increase the availability of nutrients for Legionella during bacterial replication.

Multiple modifications by SetA occurred on threonine and/or serine residues of the target proteins. A chemoenzymatic proteomics approach using the substrate analogue UDP-6-azido-6-deoxyglucose and click-chemistry for labeling, isolation, and profiling of modified proteins resulted in the discovery of 317 serine/threonine glucosylated sites on 276 eukaryotic protein substrates [52]. This allowed identification of a S/T-X-L-P/G sequence motif, which is preferably glucosylated by SetA. Promiscuous binding of SetA to many target proteins was also independently confirmed by the cross-linking of ectopicallyexpressed SetA with its interactors in intact cells followed by affinity purification-mass spectrometry [94]. These studies suggested that SetA potentially has a large number of host cell targets.

Structure-function studies revealed that SetA, similar to Lgt3, contains a $\mathrm{COOH}-$ terminal lipid-binding domain (Figure 1B). While the role of this domain in Lgt3 remains to be determined, it was demonstrated that it exerts control over SetA's enzymatic activity. It specifically bound PI3P with high affinity, targeting ectopically expressed SetA to the PI3P-rich membranes of early endosomes in uninfected cells and to the LCV upon infection, spatially restricting the activity of the effector [53,91]. Moreover, lipid binding strongly increased the glucosyltransferase activity of the effector, which could prevent undesired activity within the bacteria [92]. Combined, this seems to represent an elegant example of fine tuning of the catalytic activity of a bacterial effector, leading to maximal activity after delivery into the host cell and recruitment to specific target membranes.

A comprehensive validation of targets of SetA in infected cells has not been undertaken yet, but the glucosylation of a component of retrograde recycling machinery Snx1 [52,95] and the small GTPase Rab1 [94] was confirmed in L. pneumophila-infected HeLa or HEK293T cells overexpressing the targets (Figure 1C).

The role of Snx1 and its modification for infection is not clarified in detail. However, SetA might support other effectors, for example RidL, in the manipulation of retrograde trafficking $[96,97]$. In contrast to Snx1, Rab1 is a very well-characterized target for L. pneumophila effectors. The bacterial proteins control the full GTPase cycle, activating and recruiting (SidM) and later deactivating and releasing Rab1 (LepB) from the LCV through their GEF and GAP activities, respectively [98]. Reversible AMPylation and posphocholination by the effectors SidM and AnkX change the interactomes of Rab1 and control its state $[99,100]$. SetA preferentially modified the GDP-bound form of Rab1 at a single glu- 
cosylation site, threonine-75, located in its switch-II region [94]. The modification does not reduce GTP loading of the protein, but inhibits the intrinsic GTPase activity of Rab1 and prevents the interaction with the GDP dissociation inhibitor (GDI) [94]. Similar to the modification of serine- 53 of eEF1A by Lgt1, the glucosylation of threonine-75 in Rab1 competes with the phosphorylation of this residue by TGF- $\beta$ activated kinase 1 (Tak1), which is a prerequisite for the normal function of Rab1 suppressing the interaction with the GDI and enhancing membrane association [101]. Rab1 phosphorylation was reduced by L. pneumophila wild type, but not a T4SS-deficient strain.

Interestingly, modification by SidM or AnkX could follow glucosylation, but not the other way round in vitro; however, in infected cells, Rab1 carrying two modifications was not detected [94]. While a L. pneumophila $\Delta$ set $A$ mutant did not display a Rab1 recruitment defect [94], the enzymatic activity of SetA might override control by endogenous Tak1, increase the pool of the membrane-associated, GTP-bound (i.e., active) form of Rab1, and thus in concert with several other effectors contribute to the formation of the LCV.

SetA has the potential to modify a large pool of diverse substrate proteins with various structural folds, functional roles, and assorted locations by recognizing a short consensus sequence. Therefore, additional targets apart from Rab1 and Snx1 during infection of macrophages or protozoan hosts could exist. Given that SetA competes with the endogenous modification of Rab1 by Tak1, the identification of additional targets and the glucosylation sites might be the basis to reveal previously unknown post-translational regulatory mechanisms in eukaryotes.

\section{L. pneumophila Translocated Protein M (LtpM)}

Lgt1-3 and SetA belong to GT-A type glucosyltransferases of families 88 and 32, respectively, in the carbohydrate active enzymes database (http: / / www.cazy.org [102] as accessed on the 1 February 2022). Recently, a new type of glucosyltransferase was identified in L. pneumophila strain Paris [54]. Similar to SetA, the new glycosyltransferase effector LtpM (Lpp0356, WP_011212979.1) is a $72 \mathrm{kDa}$ protein and consists of $\mathrm{NH}_{2}$-terminal enzymatic and $\mathrm{COOH}$-terminal lipid-binding domains (Figure 1B). The latter bound PI3P with an affinity similar to that of SetA and demonstrated specific targeting to membranes rich in this PIP. The $\mathrm{NH}_{2}$-terminal domain of LtpM shows remote sequence similarity to the glycosyltransferase domain of the insecticidal protein toxin PaTox of the entomopathogen Photorhabdus asymbiotica [49] and to SetA [91]. In contrast to these glycosyltransferases, LtpM, however, features a DxN instead of the classical DxD motif found in GT-A superfamily members [54]. Recombinant LtpM showed glucohydrolase, autoglucosylation, and glucosyltransferase activities and uses UDP-glucose as the preferred sugar donor to modify the artificial substrate BSA [54]. Similar to SetA, phosphoinositide binding enhanced the glucosyltransferase activity. Substitution of the catalytic DxN with NxN or even DxD motifs rendered the enzyme inactive, demonstrating that the catalytic core of LtpM is optimized for and depends on the DxN motif. Interestingly, in contrast to Lgt1-3, SetA or other GT-A type glycosyltransferases LtpM did not rely on divalent metal ions for catalysis [54]. Combined, this indicates that LtpM represents a new type of glycosyltransferase with a new active site structure.

Ectopic expression of LtpM caused strong toxicity in S. cerevisiae and moderate toxicity in mammalian cells, suggesting subtle differences in the activity of the enzyme or the essentiality of the modified proteins. The specific substrate(s), modified by LtpM is(are) not known. Upon ectopic expression, mCherry-tagged LtpM or inactive LtpM-NxN colocalized with the early and late endosomal GTPases Rab5 and Rab7, but not with Rab6 and Rab11 [54]. The effector neither affected the retrograde transport of cholera toxin from the cell surface via endosomes to the Golgi apparatus nor caused a significant defect in the recycling of the iron carrier transferrin from endosomes to the cell surface. However, there was a significant decrease in the movement of vesicles carrying the wild type LtpM compared to the inactive protein, indicating that the effector might modulate microtubuledependent vesicle traffic [54]. 
During infection, LtpM mainly localized to the LCV surface (Figure 1C), suggesting that it could contribute to the decoupling of the LCV from the phagolysosomal pathway. However, as many other effectors are dedicated to this, it is not surprising that LtpM was not essential for intracellular replication of L. pneumophila. Identification of the actual substrates of LtpM during infection will provide clarity about its role.

\section{Substrate of Icm/Dot Transporter I (SidI)}

Recently the effector SidI (Ceg32, Lpg2504, WP_010948206.1) was proposed to be a new glycosyltransferase [14,103]. SidI is a $110 \mathrm{kDa}$ protein that is toxic upon ectopic expression in yeast and mammalian cells. SidI targets eEF1A (as do Lgt1-3) and eEF1B $\gamma$, resulting in malfunction of the host cell translation elongation complex and a shutdown of translation. Upon ectopic expression, SidI's action activates heat shock factor 1 (HSF1), inducing heat stress response genes such as $h s p 70$. During infection, SidI-dependent activation of HSF1 is detectable, but downstream signaling is not congruent with the effect of ectopic expression; for example, a significant increase of the Hsp70 protein is not observed. Most likely, this is due to the action of other effectors shaping transcription and/or the wider effector-mediated inhibition of translation [103].

SidI shares some similarity with bacterial and eukaryotic GT-B type glycosyltransferases, and recombinant SidI hydrolyzed specifically GDP-mannose, suggesting that it could be a mannosyltransferase (Figure 1A) [104]. Notably, only the entire, intact protein showed maximal sugar hydrolase activity. The glycosylation of host cell targets and the mechanistic role of this activity for the inhibition of translation still need to be demonstrated.

While sharing similar targets, SidI is, unlike Lgt1, expressed during exponential growth and the respective effects on host cell signaling seem not redundant. Nevertheless, the a L. pneumophila $\Delta$ sidI mutant does not display an intracellular growth defect in mouse macrophages or $D$. discoideum, indicating that other functionally redundant effectors exist $[103,105]$.

The activity of SidI is tightly controlled by its metaeffector MesI (Lpg2505), encoded adjacent to SidI [104,105]. MesI binds SidI and thereby suppresses the inhibition of translation [106] [104,106,107]. Complex formation with MesI does not block the binding of SidI to eEF1A, but it reduces its glycosyl hydrolase activity. In addition, interaction of MesI with SidI already in the bacteria might also modulate the translocation of SidI; however, this needs further validation, as different studies report inconsistent findings, probably due to different experimental conditions and detection methods [104,106]. Apart from the direct binding shown for SidI/MesI, numerous examples of effector-effector interactions are known. This significantly expands the modes of regulation of effector activities [108].

Interestingly, unlike the L. pneumophila $\Delta$ sidI mutant, the L. pneumophila $\Delta$ mesI mutant shows attenuated replication in mice, macrophages, and Acanthamoeba castellanii [105,106]. The production of SidI precedes MesI during growth in broth, suggesting that the activity of SidI is beneficial early, but damaging late during infection. Whether deactivation of SidI at the later stage is needed to relieve the block in translation again, and/or prevent undesired off-target activity of SidI, which could block processes vital for replication or lead to an effector-triggered immune response, remains to be elucidated.

\section{Conclusions}

The glycosylation of host proteins as a bacterial virulence strategy was first discovered during the investigation of secreted bacterial toxins, proteinaceous poisons causing pathologies ranging from local tissue damage to systemic intoxication and death of the host. Not much later, several effector proteins in the diverse Dot/Icm T4SS effector repertoire of L. pneumophila were also found to have glycosyltransferase activity. In vitro studies of these effectors indicated their cytotoxic potential; however, it is emerging that during infection these effectors are not lethal and rather perform the precise and subtle manipulations of host processes. Moreover, with our increasing knowledge of eukaryotic posttranslational 
regulatory systems, it becomes apparent that the glycosylation by L. pneumophila effectors often occurs on neuralgic protein sites, obstructing or mimicking endogenous modifications. Future investigation of L. pneumophila glycosyltransferase effectors therefore promises to reveal new aspects of host subversion by pathogens, and, at the same time, advance our understanding of eukaryotic cell physiology.

Author Contributions: Y.B. and G.N.S. compiled the first full draft with support from N.L. All authors edited and revised the manuscript to shape the final version. All authors have read and agreed to the published version of the manuscript.

Funding: G.N.S. was supported by institutional funding from Queen's University Belfast in the build-up to BBSRC grant BB/W002752/1.

Acknowledgments: Figure 1 was created with BioRender.com (last accessed date is 22 October 2021)

Conflicts of Interest: G.N.S., N.L. and Y.B. have no conflicts of interest to declare.

\section{References}

1. McDade, J.E.; Shepard, C.C.; Fraser, D.W.; Tsai, T.R.; Redus, M.A.; Dowdle, W.R. Legionnaires' disease: Isolation of a bacterium and demonstration of its role in other respiratory disease. N. Engl. J. Med 1977, 297, 1197-1203. [CrossRef]

2. Fraser, D.W.; Deubner, D.C.; Hill, D.L.; Gilliam, D.K. Nonpneumonic, short-incubation-period Legionellosis (Pontiac fever) in men who cleaned a steam turbine condenser. Science 1979, 205, 690-691. [CrossRef] [PubMed]

3. Horwitz, M.A.; Silverstein, S.C. Legionnaires' disease bacterium (Legionella pneumophila) multiples intracellularly in human monocytes. J. Clin. Investig. 1980, 66, 441-450. [CrossRef] [PubMed]

4. Berger, K.H.; Isberg, R.R. Two distinct defects in intracellular growth complemented by a single genetic locus in Legionella pneumophila. Mol. Microbiol. 1993, 7, 7-19. [CrossRef] [PubMed]

5. Sadosky, A.B.; Wiater, L.A.; Shuman, H.A. Identification of Legionella pneumophila genes required for growth within and killing of human macrophages. Infect. Immun. 1993, 61, 5361-5373. [CrossRef]

6. Kellermann, M.; Scharte, F.; Hensel, M. Manipulation of host cell organelles by intracellular pathogens. Int. J. Mol. Sci. 2021, 22, 6484. [CrossRef]

7. Mondino, S.; Schmidt, S.; Rolando, M.; Escoll, P.; Gomez-Valero, L.; Buchrieser, C. Legionnaires' Disease: State of the art knowledge of pathogenesis mechanisms of Legionella. Annu. Rev. Pathol. 2020, 15, 439-466. [CrossRef]

8. Vozandychova, V.; Stojkova, P.; Hercik, K.; Rehulka, P.; Stulik, J. The ubiquitination system within bacterial host-pathogen interactions. Microorganisms 2021, 9, 638. [CrossRef]

9. Omotade, T.O.; Roy, C.R. Manipulation of host cell organelles by intracellular pathogens. Microbiol. Spectr. 2019, 7, 7-2. [CrossRef]

10. Best, A.; Abu Kwaik, Y. Evolution of the arsenal of Legionella pneumophila effectors to modulate protist hosts. $m$ Bio 2018, 9, e01313-18. [CrossRef]

11. Joseph, A.M.; Shames, S.R. Affecting the effectors: Regulation of Legionella pneumophila effector function by metaeffectors. Pathogens 2021, 10, 108. [CrossRef] [PubMed]

12. Brüggemann, H.; Hagman, A.; Jules, M.; Sismeiro, O.; Dillies, M.-A.; Gouyette, C.; Kunst, F.; Steinert, M.; Heuner, K.; Coppée, J.-Y.; et al Virulence strategies for infecting phagocytes deduced from the in vivo transcriptional program of Legionella pneumophila. Cell. Microbiol. 2006, 8, 1228-1240. [CrossRef] [PubMed]

13. Byrne, B.; Swanson, M.S. Expression of Legionella pneumophila virulence traits in response to growth conditions. Infect. Immun. 1998, 66, 3029-3034. [CrossRef] [PubMed]

14. Zusman, T.; Aloni, G.; Halperin, E.; Kotzer, H.; Degtyar, E.; Feldman, M.; Segal, G. The response regulator PmrA is a major regulator of the icm/dot type IV secretion system in Legionella pneumophila and Coxiella burnetii. Mol. Microbiol. 2007, 63, 1508-1523. [CrossRef]

15. Ninio, S.; Roy, C.R. Effector proteins translocated by Legionella pneumophila: Strength in numbers. Trends Microbiol. 2007, 15, 372-380. [CrossRef]

16. Huang, L.; Boyd, D.; Amyot, W.M.; Hempstead, A.D.; Luo, Z.Q.; O'Connor, T.J.; Chen, C.; Machner, M.; Montminy, T.; Isberg, R.R. The E Block motif is associated with Legionella pneumophila translocated substrates. Cell. Microbiol. 2011, 13, 227-245. [CrossRef]

17. Burstein, D.; Zusman, T.; Degtyar, E.; Viner, R.; Segal, G.; Pupko, T. Genome-scale identification of Legionella pneumophila effectors using a machine learning approach. PLoS Pathogens 2009, 5, e1000508. [CrossRef]

18. Zhu, W.; Banga, S.; Tan, Y.; Zheng, C.; Stephenson, R.; Gately, J.; Luo, Z.-Q. Comprehensive identification of protein substrates of the Dot/Icm type IV transporter of Legionella pneumophila. PLoS ONE 2011, 6, e17638. [CrossRef]

19. Gaspar, A.H.; Machner, M.P. VipD is a Rab5-activated phospholipase A1 that protects Legionella pneumophila from endosomal fusion. Proc. Natl. Acad. Sci. USA 2014, 111, 4560-4565. [CrossRef]

20. Hervet, E.; Charpentier, X.; Vianney, A.; Lazzaroni, J.C.; Gilbert, C.; Atlan, D.; Doublet, P. Protein kinase LegK2 is a type IV secretion system effector involved in endoplasmic reticulum recruitment and intracellular replication of Legionella pneumophila. Infect. Immun. 2011, 79, 1936-1950. [CrossRef] 
21. Ge, J.; Xu, H.; Li, T.; Zhou, Y.; Zhang, Z.; Li, S.; Liu, L.; Shao, F. A Legionella type IV effector activates the NF-kappaB pathway by phosphorylating the IkappaB family of inhibitors. Proc. Natl. Acad. Sci. USA 2009, 106, 13725-13730. [CrossRef] [PubMed]

22. Black, M.H.; Osinski, A.; Park, G.J.; Gradowski, M.; Servage, K.A.; Pawlowski, K.; Tagliabracci, V.S. A Legionella effector ADP-ribosyltransferase inactivates glutamate dehydrogenase. J. Biol. Chem. 2021, 296, 100301. [CrossRef]

23. Kim, L.; Kwon, D.H.; Kim, B.H.; Kim, J.; Park, M.R.; Park, Z.-Y.; Song, H.K. Structural and biochemical study of the mono-ADPribosyltransferase domain of SdeA, a ubiquitylating/deubiquitylating enzyme from Legionella pneumophila. J. Mol. Biol. 2018, 430, 2843-2856. [CrossRef] [PubMed]

24. Michard, C.; Doublet, P. Post-translational modifications are key players of the Legionella pneumophila infection strategy. Front. Microbiol. 2015, 6, 87. [CrossRef]

25. Sulpizio, A.G.; Minelli, M.E.; Mao, Y. Glutamylation of bacterial ubiquitin ligases by a Legionella pseudokinase. Trends Microbiol. 2019, 27, 967-969. [CrossRef] [PubMed]

26. Price, C.T.D.; Abu Kwaik, Y. Evolution and adaptation of Legionella pneumophila to manipulate the ubiquitination machinery of Its amoebae and mammalian hosts. Biomolecules 2021, 11, 112. [CrossRef]

27. Hilbi, H.; Weber, S.; Finsel, I. Anchors for effectors: Subversion of phosphoinositide lipids by Legionella. Front. Microbiol. 2011, 2, 91. [CrossRef]

28. Hilbi, H.; Nagai, H.; Kubori, T.; Roy, C.R. Subversion of host membrane dynamics by the Legionella Dot/Icm type IV secretion system. In Type IV Secretion in Gram-Negative and Gram-Positive Bacteria; Backert, S., Grohmann, E., Eds.; Springer International Publishing: Cham, Switzerland, 2017; pp. 221-242.

29. Shi, X.; Halder, P.; Yavuz, H.; Jahn, R.; Shuman, H.A. Direct targeting of membrane fusion by SNARE mimicry: Convergent evolution of Legionella effectors. Proc. Natl. Acad. Sci. USA 2016, 113, 8807-8812. [CrossRef]

30. Just, I.; Fritz, G.; Aktories, K.; Giry, M.; Popoff, M.R.; Boquet, P.; Hegenbarth, S.; von Eichel-Streiber, C. Clostridium difficile toxin B acts on the GTP-binding protein Rho. J. Biol. Chem. 1994, 269, 10706-10712. [CrossRef]

31. Jank, T.; Belyi, Y.; Aktories, K. Bacterial glycosyltransferase toxins. Cell. Microbiol. 2015, 17, 1752-1765. [CrossRef]

32. Jank, T.; Lang, A.E.; Aktories, K. Rho-modifying bacterial protein toxins from Photorhabdus species. Toxicon 2016, 116, 17-22. [CrossRef] [PubMed]

33. Belyi, I.; Popoff, M.R.; Cianciotto, N.P. Purification and characterization of a UDP-glucosyltransferase produced by Legionella pneumophila. Infect. Immun. 2003, 71, 181-186. [CrossRef]

34. Belyi, Y.; Niggeweg, R.; Opitz, B.; Vogelsgesang, M.; Hippenstiel, S.; Wilm, M.; Aktories, K. Legionella pneumophila glucosyltransferase inhibits host elongation factor 1A. Proc. Natl. Acad. Sci. USA 2006, 103, 16953-16958. [CrossRef] [PubMed]

35. Nau, G.J.; Horzempa, J.; O’Dee, D.; Brown, M.J.; Russo, B.C.; Hernandez, A.; Dillon, S.T.; Cheng, J.; Kane, L.P.; Sanker, S.; et al. A predicted Francisella tularensis DXD-motif glycosyltransferase blocks immune activation. Virulence 2019, 10, 643-656. [CrossRef]

36. Li, S.; Zhang, L.; Yao, Q.; Li, L.; Dong, N.; Rong, J.; Gao, W.; Ding, X.; Sun, L.; Chen, X.; et al. Pathogen blocks host death receptor signalling by arginine GlcNAcylation of death domains. Nature 2013, 501, 242-246. [CrossRef] [PubMed]

37. Pearson, J.S.; Giogha, C.; Ong, S.Y.; Kennedy, C.L.; Kelly, M.; Robinson, K.S.; Lung, T.W.; Mansell, A.; Riedmaier, P.; Oates, C.V.; et al. A type III effector antagonizes death receptor signalling during bacterial gut infection. Nature 2013, 501, 247-251. [CrossRef] [PubMed]

38. Brown, N.F.; Coombes, B.K.; Bishop, J.L.; Wickham, M.E.; Lowden, M.J.; Gal-Mor, O.; Goode, D.L.; Boyle, E.C.; Sanderson, K.L.; Finlay, B.B. Salmonella phage ST64B encodes a member of the SseK/NleB effector family. PLoS ONE 2011, 6, e17824. [CrossRef]

39. Jank, T.; Eckerle, S.; Steinemann, M.; Trillhaase, C.; Schimpl, M.; Wiese, S.; van Aalten, D.M.; Driever, W.; Aktories, K. Tyrosine glycosylation of Rho by Yersinia toxin impairs blastomere cell behaviour in zebrafish embryos. Nat. Commun. $2015,6,7807$. [CrossRef]

40. Araujo-Garrido, J.L.; Bernal-Bayard, J.; Ramos-Morales, F. Type III secretion effectors with arginine N-glycosyltransferase activity. Microorganisms 2020, 8, 357. [CrossRef]

41. Pan, X.; Luo, J.; Li, S. Bacteria-catalyzed arginine glycosylation in pathogens and host. Front. Cell. Infect. Microbiol. 2020, 10, 185. [CrossRef]

42. Koh, E.; Cho, H.-S. NleB/SseKs ortholog effectors as a general bacterial monoglycosyltransferase for eukaryotic proteins. Curr. Opin. Struct. Biol. 2021, 68, 215-223. [CrossRef] [PubMed]

43. Just, I.; Wilm, M.; Selzer, J.; Rex, G.; von Eichel-Streiber, C.; Mann, M.; Aktories, K. The enterotoxin from Clostridium difficile (ToxA) monoglucosylates the Rho proteins. J. Biol. Chem. 1995, 270, 13932-13936. [CrossRef] [PubMed]

44. Sun, Y.; Willis, L.M.; Batchelder, H.R.; Nitz, M. Site specific protein O-glucosylation with bacterial toxins. Chem. Commun. (Camb) 2016, 52, 13024-13026. [CrossRef] [PubMed]

45. Just, I.; Selzer, J.; Hofmann, F.; Green, G.A.; Aktories, K. Inactivation of Ras by Clostridium sordellii lethal toxin-catalyzed glucosylation. J. Biol. Chem. 1996, 271, 10149-10153. [CrossRef]

46. Genth, H.; Hofmann, F.; Selzer, J.; Rex, G.; Aktories, K.; Just, I. Difference in protein substrate specificity between hemorrhagic toxin and lethal toxin from Clostridium sordellii. Biochem. Biophys. Res. Commun. 1996, 229, 370-374. [CrossRef]

47. Amimoto, K.; Noro, T.; Oishi, E.; Shimizu, M. A novel toxin homologous to large clostridial cytotoxins found in culture supernatant of Clostridium perfringens type C. Microbiology (Reading) 2007, 153, 1198-1206. [CrossRef]

48. Selzer, J.; Hofmann, F.; Rex, G.; Wilm, M.; Mann, M.; Just, I.; Aktories, K. Clostridium novyi alpha-toxin-catalyzed incorporation of GlcNAc into Rho subfamily proteins. J. Biol. Chem. 1996, 271, 25173-25177. [CrossRef] 
49. Jank, T.; Bogdanovic, X.; Wirth, C.; Haaf, E.; Spoerner, M.; Bohmer, K.E.; Steinemann, M.; Orth, J.H.; Kalbitzer, H.R.; Warscheid, B.; et al. A bacterial toxin catalyzing tyrosine glycosylation of Rho and deamidation of Gq and Gi proteins. Nat. Struct. Molec. Biol. 2013, 20, 1273-1280. [CrossRef]

50. Ost, G.S.; Wirth, C.; Bogdanović, X.; Kao, W.C.; Schorch, B.; Aktories, P.J.K.; Papatheodorou, P.; Schwan, C.; Schlosser, A.; Jank, T.; et al. Inverse control of Rab proteins by Yersinia ADP-ribosyltransferase and glycosyltransferase related to clostridial glucosylating toxins. Sci. Adv. 2020, 6, eaaz2094. [CrossRef]

51. Belyi, Y.; Stahl, M.; Sovkova, I.; Kaden, P.; Luy, B.; Aktories, K. Region of elongation factor 1A1 involved in substrate recognition by Legionella pneumophila glucosyltransferase Lgt1: Identification of Lgt1 as a retaining glucosyltransferase. J. Biol. Chem. 2009, 284, 20167-20174. [CrossRef]

52. Gao, L.; Song, Q.; Liang, H.; Zhu, Y.; Wei, T.; Dong, N.; Xiao, J.; Shao, F.; Lai, L.; Chen, X. Legionella effector SetA as a general O-glucosyltransferase for eukaryotic proteins. Nat. Chem. Biol. 2019, 15, 213-216. [CrossRef]

53. Heidtman, M.; Chen, E.J.; Moy, M.-Y.; Isberg, R.R. Large-scale identification of Legionella pneumophila Dot/Icm substrates that modulate host cell vesicle trafficking pathways. Cell. Microbiol. 2009, 11, 230-248. [CrossRef] [PubMed]

54. Levanova, N.; Mattheis, C.; Carson, D.; To, K.N.; Jank, T.; Frankel, G.; Aktories, K.; Schroeder, G.N. The Legionella effector LtpM is a new type of phosphoinositide-activated glucosyltransferase. J. Biol. Chem. 2019, 294, 2862-2879. [CrossRef] [PubMed]

55. Park, J.B.; Kim, Y.H.; Yoo, Y.; Kim, J.; Jun, S.H.; Cho, J.W.; El Qaidi, S.; Walpole, S.; Monaco, S.; Garcia-Garcia, A.A.; et al. Structural basis for arginine glycosylation of host substrates by bacterial effector proteins. Nat. Commun. 2018, 9, 4283. [CrossRef] [PubMed]

56. El Qaidi, S.; Chen, K.; Halim, A.; Siukstaite, L.; Rueter, C.; Hurtado-Guerrero, R.; Clausen, H.; Hardwidge, P.R. NleB/SseK effectors from Citrobacter rodentium, Escherichia coli, and Salmonella enterica display distinct differences in host substrate specificity. J. Biol. Chem. 2017, 292, 11423-11430. [CrossRef]

57. Levanova, N.; Tabakova, I.; Jank, T.; Belyi, Y. Purification and analysis of effector glucosyltransferase Lgt1 from Legionella pneumophila. Methods Mol. Biol. 2019, 1921, 277-287.

58. Just, I.; Selzer, J.; Wilm, M.; von Eichel-Streiber, C.; Mann, M.; Aktories, K. Glucosylation of Rho proteins by Clostridium difficile toxin B. Nature 1995, 375, 500-503. [CrossRef]

59. Belyi, Y.; Jank, T.; Aktories, K. Effector glycosyltransferases in Legionella. Front. Microbiol. 2011, 2, 76. [CrossRef]

60. Sadretdinova, O.V.; Liuk, K.; Karpova, T.I.; Belyi, I.F.; Tartakovskii, I.S. Prevalence of glucosyl transferase Lgt among Legionella pneumophila strains isolated from various sources. Zhurnal Mikrobiol. Epidemiol. Immunobiol. 2012, 3, 8-12.

61. de Felipe, K.S.; Glover, R.T.; Charpentier, X.; Anderson, O.R.; Reyes, M.; Pericone, C.D.; Shuman, H.A. Legionella eukaryotic-like type IV substrates interfere with organelle trafficking. PLoS. Pathog. 2008, 4, e1000117. [CrossRef]

62. de Felipe, K.S.; Pampou, S.; Jovanovic, O.S.; Pericone, C.D.; Ye, S.F.; Kalachikov, S.; Shuman, H.A. Evidence for acquisition of Legionella type IV secretion substrates via interdomain horizontal gene transfer. J. Bacteriol. 2005, 187, 7716-7726. [CrossRef] [PubMed]

63. Hurtado-Guerrero, R.; Zusman, T.; Pathak, S.; Ibrahim, A.F.; Shepherd, S.; Prescott, A.; Segal, G.; van Aalten, D.M. Molecular mechanism of elongation factor 1A inhibition by a Legionella pneumophila glycosyltransferase. Biochem. J. 2010, 426, 281-292. [CrossRef]

64. Belyi, Y.; Tabakova, I.; Stahl, M.; Aktories, K. Lgt: A family of cytotoxic glucosyltransferases produced by Legionella pneumophila. J. Bacteriol. 2008, 190, 3026-3035. [CrossRef] [PubMed]

65. Ramakrishnan, V. Ribosome structure and the mechanism of translation. Cell 2002, 108, 557-572. [CrossRef]

66. Belyi, Y.; Tartakovskaya, D.; Tais, A.; Fitzke, E.; Tzivelekidis, T.; Jank, T.; Rospert, S.; Aktories, K. Elongation factor 1A is the target of growth inhibition in yeast caused by Legionella pneumophila glucosyltransferase Lgt1. J. Biol. Chem. 2012, 287, 26029-26037. [CrossRef] [PubMed]

67. Tzivelekidis, T.; Jank, T.; Pohl, C.; Schlosser, A.; Rospert, S.; Knudsen, C.R.; Rodnina, M.V.; Belyi, Y.; Aktories, K. AminoacyltRNA-charged eukaryotic elongation factor 1A is the bona fide substrate for Legionella pneumophila effector glucosyltransferases. PLoS ONE 2011, 6, e29525. [CrossRef]

68. Andersen, G.R.; Pedersen, L.; Valente, L.; Chatterjee, I.; Kinzy, T.G.; Kjeldgaard, M.; Nyborg, J. Structural basis for nucleotide exchange and competition with tRNA in the yeast elongation factor complex eEF1A:eEF1Balpha. Mol. Cell 2000, 6, 1261-1266. [CrossRef]

69. Crepin, T.; Shalak, V.F.; Yaremchuk, A.D.; Vlasenko, D.O.; McCarthy, A.; Negrutskii, B.S.; Tukalo, M.A.; El'skaya, A.V. Mammalian translation elongation factor eEF1A2: X-ray structure and new features of GDP/GTP exchange mechanism in higher eukaryotes. Nucleic Acids Res. 2014, 42, 12939-12948. [CrossRef]

70. Piazzi, M.; Bavelloni, A.; Faenza, I.; Blalock, W.; Urbani, A.; D’Aguanno, S.; Fiume, R.; Ramazzotti, G.; Maraldi, N.M.; Cocco, L. eEF1A phosphorylation in the nucleus of insulin-stimulated C2C12 myoblasts: Ser ${ }^{53}$ is a novel substrate for protein kinase $\mathrm{C} \beta \mathrm{I}$. Mol. Cell. Proteom. 2010, 9, 2719-2728. [CrossRef]

71. Mateyak, M.K.; He, D.; Sharma, P.; Kinzy, T.G. Mutational analysis reveals potential phosphorylation sites in eukaryotic elongation factor 1A that are important for its activity. FEBS Lett. 2021, 595, 2208-2220. [CrossRef]

72. Mills, A.; Gago, F. On the need to tell apart fraternal twins eEF1A1 and eEF1A2, and their respective outfits. Int. J. Mol. Sci. 2021, 22, 6973. [CrossRef]

73. Carriles, A.A.; Mills, A.; Munoz-Alonso, M.J.; Gutierrez, D.; Dominguez, J.M.; Hermoso, J.A.; Gago, F. Structural cues for understanding eEF1A2 moonlighting. ChemBioChem 2021, 22, 374-391. [CrossRef] [PubMed] 
74. Abbas, W.; Kumar, A.; Herbein, G. The eEF1A proteins: At the crossroads of oncogenesis, apoptosis, and viral infections. Front. Oncol. 2015, 5, 75. [CrossRef] [PubMed]

75. Lamberti, A.; Caraglia, M.; Longo, O.; Marra, M.; Abbruzzese, A.; Arcari, P. The translation elongation factor 1A in tumorigenesis, signal transduction and apoptosis: Review article. Amino Acids 2004, 26, 443-448. [CrossRef] [PubMed]

76. Li, G.; Liu, H.; Luo, Z.Q.; Qiu, J. Modulation of phagosome phosphoinositide dynamics by a Legionella phosphoinositide 3-kinase. EMBO Rep. 2021, 22, e51163. [CrossRef]

77. Swart, A.L.; Hilbi, H. Phosphoinositides and the fate of Legionella in phagocytes. Front. Immunol. 2020, 11, 25. [CrossRef]

78. Nelson, R.J.; Ziegelhoffer, T.; Nicolet, C.; Werner-Washburne, M.; Craig, E.A. The translation machinery and 70 kd heat shock protein cooperate in protein synthesis. Cell 1992, 71, 97-105. [CrossRef]

79. Buskirk, A.R.; Green, R. Ribosome pausing, arrest and rescue in bacteria and eukaryotes. Philos. Trans. R. Soc. B Biol. Sci. 2017, 372, 20160183. [CrossRef]

80. Belyi, Y.; Jank, T.; Aktories, K. Cytotoxic glucosyltransferases of Legionella pneumophila. Curr. Top. Microbiol. Immunol. 2013, 376, 211-226.

81. de Jesús-Díaz, D.A.; Murphy, C.; Sol, A.; Dorer, M.; Isberg, R.R. Host cell S phase restricts Legionella pneumophila intracellular replication by destabilizing the membrane-bound replication compartment. mBio 2017, 8, e02345-16. [CrossRef]

82. Sol, A.; Lipo, E.; de Jesus-Diaz, D.A.; Murphy, C.; Devereux, M.; Isberg, R.R. Legionella pneumophila translocated translation inhibitors are required for bacterial-induced host cell cycle arrest. Proc. Natl. Acad. Sci. USA 2019, 116, 3221-3228. [CrossRef]

83. Treacy-Abarca, S.; Mukherjee, S. Legionella suppresses the host unfolded protein response via multiple mechanisms. Nat. Commun. 2015, 6, 7887. [CrossRef]

84. Hempstead, A.D.; Isberg, R.R. Inhibition of host cell translation elongation by Legionella pneumophila blocks the host cell unfolded protein response. Proc. Natl. Acad. Sci. USA 2015, 112, E6790-E6797. [CrossRef]

85. Fontana, M.F.; Banga, S.; Barry, K.C.; Shen, X.; Tan, Y.; Luo, Z.-Q.; Vance, R.E. Secreted bacterial effectors that inhibit host protein synthesis are critical for induction of the innate immune response to virulent Legionella pneumophila. PLoS Pathog. 2011, 7, e1001289. [CrossRef] [PubMed]

86. Fontana, M.F.; Shin, S.; Vance, R.E. Activation of host mitogen-activated protein kinases by secreted Legionella pneumophila effectors that inhibit host protein translation. Infect. Immun. 2012, 80, 3570-3575. [CrossRef] [PubMed]

87. Asrat, S.; Dugan, A.S.; Isberg, R.R. , The frustrated host response to Legionella pneumophila is bypassed by MyD88-dependent translation of pro-inflammatory cytokines. PLoS Pathog. 2014, 10, e1004229. [CrossRef]

88. Belyi, Y. Targeting Eukaryotic mRNA Translation by Legionella pneumophila. Front. Mol. Biosci. 2020, 7, 80. [CrossRef] [PubMed]

89. Park, J.M.; Ghosh, S.; O'Connor, T.J. Combinatorial selection in amoebal hosts drives the evolution of the human pathogen Legionella pneumophila. Nat. Microbiol. 2020, 5, 599-609. [CrossRef]

90. Nachmias, N.; Zusman, T.; Segal, G. Study of Legionella effector domains revealed novel and prevalent phosphatidylinositol 3-phosphate binding domains. Infect. Immun. 2019, 87, e00153-19. [CrossRef]

91. Jank, T.; Bohmer, K.E.; Tzivelekidis, T.; Schwan, C.; Belyi, Y.; Aktories, K. Domain organization of Legionella effector SetA. Cel. Microbiol. 2012, 14, 852-868. [CrossRef]

92. Levanova, N.; Steinemann, M.; Bohmer, K.E.; Schneider, S.; Belyi, Y.; Schlosser, A.; Aktories, K.; Jank, T. Characterization of the glucosyltransferase activity of Legionella pneumophila effector SetA. Naunyn-Schmiedeberg Arch. Pharmacol. 2019, 392, 69-79. [CrossRef] [PubMed]

93. Beck, W.H.J.; Kim, D.; Das, J.; Yu, H.; Smolka, M.B.; Mao, Y. Glucosylation by the Legionella effector SetA promotes the nuclear localization of the transcription factor TFEB. iScience 2020, 23, 101300. [CrossRef]

94. Wang, Z.; McCloskey, A.; Cheng, S.; Wu, M.; Xue, C.; Yu, Z.; Fu, J.; Liu, Y.; Luo, Z.Q.; Liu, X. Regulation of the small GTPase Rab1 function by a bacterial glucosyltransferase. Cell. Discov. 2018, 4, 53. [CrossRef] [PubMed]

95. Norris, A.; Grant, B.D. Endosomal microdomains: Formation and function. Curr. Opin. Cell Biol. 2020, 65, 86-95. [CrossRef] [PubMed]

96. Bärlocher, K.; Welin, A.; Hilbi, H. Formation of the Legionella replicative compartment at the crossroads of retrograde trafficking. Front. Cell. Infect. Microbiol. 2017, 7, 482. [CrossRef]

97. Finsel, I.; Ragaz, C.; Hoffmann, C.; Harrison, C.F.; Weber, S.; van Rahden, V.A.; Johannes, L.; Hilbi, H. The Legionella effector RidL inhibits retrograde trafficking to promote intracellular replication. Cell Host Microbe 2013, 14, 38-50. [CrossRef]

98. Itzen, A.; Goody, R.S. Covalent coercion by Legionella pneumophila. Cell Host Microbe 2011, 10, 89-91. [CrossRef]

99. Goody, P.R.; Heller, K.; Oesterlin, L.K.; Muller, M.P.; Itzen, A.; Goody, R.S. Reversible phosphocholination of Rab proteins by Legionella pneumophila effector proteins. EMBO J. 2012, 31, 1774-1784. [CrossRef]

100. Hardiman, C.A.; Roy, C.R. AMPylation is critical for Rab1 localization to vacuoles containing Legionella pneumophila. mBio 2014, 5, e01035-13. [CrossRef]

101. Levin, R.S.; Hertz, N.T.; Burlingame, A.L.; Shokat, K.M.; Mukherjee, S. Innate immunity kinase TAK1 phosphorylates Rab1 on a hotspot for posttranslational modifications by host and pathogen. Proc. Natl. Acad. Sci. USA 2016, 113, E4776-E4783. [CrossRef]

102. Lombard, V.; Golaconda Ramulu, H.; Drula, E.; Coutinho, P.M.; Henrissat, B. The carbohydrate-active enzymes database (CAZy) in 2013. Nucl. Acids Res. 2014, 42, D490-D495. [CrossRef] [PubMed] 
103. Shen, X.; Banga, S.; Liu, Y.; Xu, L.; Gao, P.; Shamovsky, I.; Nudler, E.; Luo, Z.-Q. Targeting eEF1A by a Legionella pneumophila effector leads to inhibition of protein synthesis and induction of host stress response. Cell. Microbiol. 2009, 11,911-926. [CrossRef] [PubMed]

104. Joseph, A.M.; Pohl, A.E.; Ball, T.J.; Abram, T.G.; Johnson, D.K.; Geisbrecht, B.V.; Shames, S.R. The Legionella pneumophila metaeffector Lpg2505 (MesI) regulates SidI-mediated translation inhibition and novel glycosyl hydrolase activity. Infect. Immun. 2020, 88, e00853-19. [CrossRef]

105. Shames, S.R.; Liu, L.; Havey, J.C.; Schofield, W.B.; Goodman, A.L.; Roy, C.R. Multiple Legionella pneumophila effector virulence phenotypes revealed through high-throughput analysis of targeted mutant libraries. Proc. Natl. Acad. Sci. USA 2017, 114, E10446-E10454. [CrossRef] [PubMed]

106. McCloskey, A.; Perri, K.; Chen, T.; Han, A.; Luo, Z.Q. The metaeffector MesI regulates the activity of the Legionella effector SidI through direct protein-protein interactions. Microbes Infect. 2021, 23, 104794. [CrossRef]

107. Machtens, D.A.; Willerding, J.M.; Eschenburg, S.; Reubold, T.F. Crystal structure of the metaeffector MesI (Lpg2505) from Legionella pneumophila. Biochem. Biophys. Res. Commun. 2020, 527, 696-701. [CrossRef]

108. Iyer, S.; Das, C. The unity of opposites: Strategic interplay between bacterial effectors to regulate cellular homeostasis. J. Biol. Chem. 2021, 297, 101340. [CrossRef] 